\title{
Inefficient Signalling, Education Arms Race and Education Inflation in China
}

\author{
Weiguang Liu \\ Correspondence: Weiguang Liu, Graduate School of Economics, Nagoya University, Aichi, Japan.
}

Received: September 10, 2018

Accepted: October 2, $2018 \quad$ Available online: October 11, 2018

doi:10.11114/aef.v5i6.3683

URL: https://doi.org/10.11114/aef.v5i6.3683

\begin{abstract}
Since the higher education expansion and education marketization from 1998, China's education inflation has become increasingly serious. And correspondingly, the income of graduates remains in a low level. This paper built a model and explained two important reasons. First, the quality of Chinese high education is relatively low, which means the signal effect of education will be less efficient. Second, every individual has an incentive to occupy higher status in the education hierarchy, which means there is a zero-sum education arms race game. I try to build a simple but powerful model in this essay to explain how thses two factors contribute to Chinese education inflation and how they intertwine with each other.
\end{abstract}

Keywords: signaling efficiency, education arms race, education inflation

\section{Introduction}

In a developing country, Chinese high education system suffers from many problems. During those problems in Chinses high education, two of them are discussed in this paper. One is the inefficient signaling problem due to the exam-oriented standard training before college (Kirkpatrick, 2011) and the ridiculously slack evaluation system in most Chinese colleges (Ma, 2013). The other is the diplomaism among an overwhelming majority of Chinese families, much of which are due to pure vanity. This diplomaism usually leads to a full-scale arms race in higher education, which is a zero-sum game for the whole society. Both problems lead to an inflation in higher education and a huge waste of social resources. In this paper, I will explain the entire process step by step.

Higher education is very important in modern society. Generally, in economics, it has two main functions. First, it can improve people's productivity through the increase of human capital, as shown in Figure 1. There are many theories based on human capital theory (Fitzsimons, 2015). Second, it helps firms to judge individuals' ability and productivity. Education has long been considered to be a very important signal about individuals' ability (Arrow, 1973; Spence 1973, 2002). The essential reason behind that is those clever guys usually need less money and effort to obtain a certain education level. So, higher education usually means higher ability.

Most students and their parents in China pursue higher education at least partly out of vanity. For many people rural areas in China, "losing face" or being despised can be intolerable. Students in those areas are eager to leave the countryside and enter a university.

In the rest of the world, education does have a show-off function. But I doubt whether there exists another country where education is so much emphasized and pursued due to non-economic reasons. To make matters worse, except some prestigious universities, most Chinese universities just can't make a clear distinction between high ability students and low ability ones. The classes in most universities are easy and don't require much intelligence and efforts to get good grades. So, one of the most important function of education - signaling function, just doesn't work. As a result, firms have difficulties to judge whether a new graduate is a low-ability one or high-ability one.

Education inflation is like currency inflation. It means there are more graduates and the value of university degrees goes down at the same time. For the above reasons, China suffers an increasingly serious education inflation problem. As a result, for many upper middle-class, being admitted to prestigious universities is what really matters.

In Section II, we present the basic model with asymmetry information and signaling efficiency. In section III, we add the education arms race into the model and get some interesting points. In section IV, we comment on some extensions that may become the future topics. In Section V, we get several conclusions. 


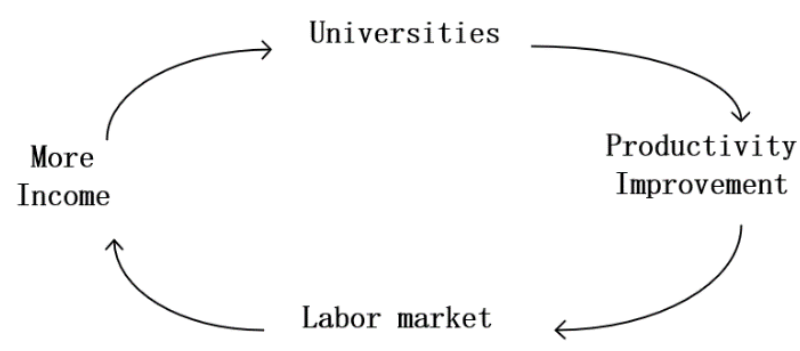

Figure 1. The reproduction cycles

Source: Drawn by the author

\section{The Model with Asymmetry Information and Signaling Efficiency}

The model in this section is built based on the reality of Chinese higher education, referring to some important models in related literature. Before we move on, we need to make it clear that in this paper, we mainly talk about normal university graduates, which is the main part of Chinese college students. And their abilities are in $[\underline{\theta}, \bar{\theta}]$. Those graduate from prestigious universities and those who drop out before high school are not in our discussion. The prestigious universities' graduates enjoy a much better education system and signaling system than others. Those who drop out before high school don't have a choice about whether receiving high education or not. So, the model in this paper can't be applied to both of them. Just as Figure 2 shows, in this essay we mainly analysis those who have abilities in $[\underline{\theta}, \bar{\theta}]$.

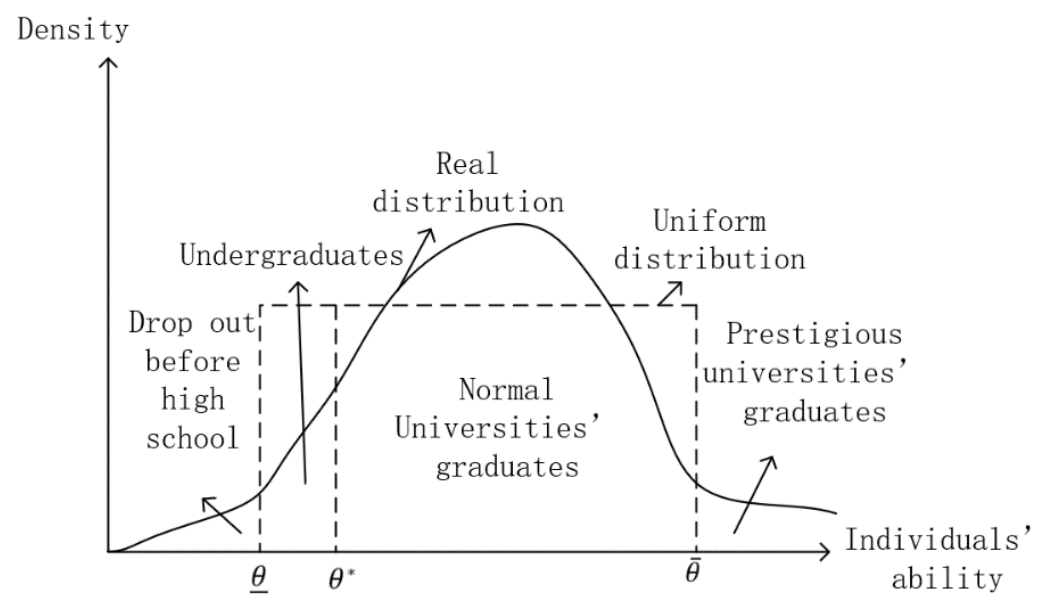

Figure 2. The real distribution of individuals' ability and simulation

Source: Drawn by the author

Another important thing is that in order to make the calculation simple, I use a uniform distribution to simulate the real distribution of individual abilities, which may cause some distortions but will not change the main conclusions.

A. The Individuals and Firms

Now we build our model by referring to Ordine and Rose's model (2017). In their model, graduates can enter both graduate and undergraduate sector, which cause mismatches. Now we don't consider the mismatches and focus on the education inflation. Consider a continuum of individuals of mass 1 characterized by heterogeneous ability $\theta$. Ability is distributed according to uniform distribution $\mathrm{F}(\theta)$, whose density function is $f(\theta)$ over an interval $[\theta, \bar{\theta}]$, where $1 \leq \underline{\theta}<\bar{\theta} .{ }^{1}$ And the critical ability level where individuals are indifferent in whether receiving higher education or not is $\theta^{*}$.

\footnotetext{
1 This ensures a productivity improvement through high education.
} 


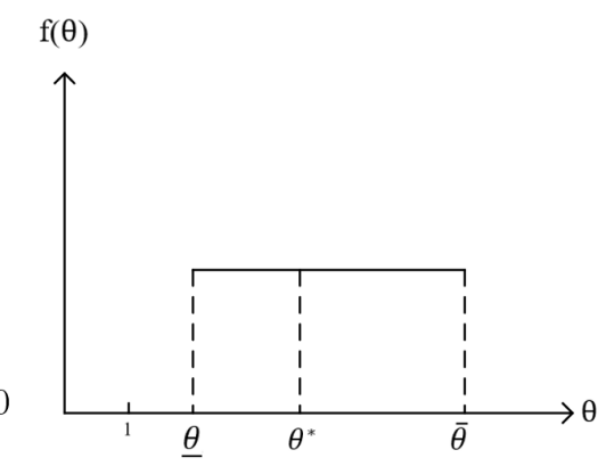

Figure 3. The distribution of individuals' ability and individuals' choice

Source: Drawn by the author

The probability density function is given $b y^{2}$ :

$$
f(\theta)=\frac{1}{\bar{\theta}-\underline{\theta}}, \theta \in[\underline{\theta}, \bar{\theta}]
$$

The final productivity is influenced by education level and individual ability:

$$
\mathrm{y}(\mathrm{E}, \theta)= \begin{cases}\theta, & \text { if } E=g \\ 1, & \text { if } E=u\end{cases}
$$

Individuals get wage according to firms' expectation on their productivity, which is also the average of all graduates:

$$
\mathrm{w}(\mathrm{E}, \theta)=\mathbb{E}[\mathrm{y}(\mathrm{E}, \theta)]=\frac{\theta^{*}+\bar{\theta}}{2}
$$

The firms pay workers their wages equal to their expected productivity. Without higher education, individuals can only participate in very simple and low-tech works, with homogeneous low productivity, which is normalized to 1 in my paper. With higher education, individual can participate in more complex and important works. And in this situation, their productivity is proportional to their ability. Here in our model, higher education is a way to get the opportunity to exert one's ability.

Because of the asymmetry information, firms can't know individuals' productivity. Firms have to judge a worker's potential ability according to their education level. Because education costs are generally negatively related to individual ability, workers with higher education level such as graduates are supposed to be more capable and productive. But for workers with the same education level, firms can't distinguish them and have to set the wage according to their expected productivity, or average productivity. ${ }^{3}$ As a result, for an individual, the productivity improvement and the wage improvement are not the same thing.

$$
\begin{gathered}
y(g, \theta)-y(u, \theta)=\theta-1 \\
w(g, \theta)-w(u, \theta)=\frac{\theta^{*}+\bar{\theta}}{2}-1
\end{gathered}
$$

$\theta^{*}$ is the critical ability. It is the lowest ability in graduates. Obviously, if $\theta>\theta^{*}$, this individual's wage improvement due to higher education is irrelevant to his ability or productivity.

\section{B. The Chinese Education System}

Education in China is divided into two distinctive parts: education before college and education in college. Each part has its own characteristics.

\footnotetext{
${ }^{2}$ We can see the probability density is constant over $\theta$. This property will provide us with great simplicity in the following discussion. In other words, we use uniform distribution instead of the more realistic normal distribution for its unparallel convenience, without losing the essential stuffs in our analysis.

3 Here I assume all the colleges are homogeneous and firms can't distinguish individuals' ability according to his graduate college. In fact, the students in prestigious universities in China is such a small proportion in all graduates that we can exclude them in our main discussion in this paper. Except a negligibly tiny number of elites, the rest colleges are more all less the same for firms.
} 
For almost all students in China, the purpose of education in elementary school, middle school and high school is to enter a college. Most educational institutions before college try their best to teach students standard knowledge and test skills. In this system, even the laziest students are forced to learn something and even the least intelligent students can get some basic knowledge through this standard training. However, those with more gifts don't have much freedom to learn at their own pace. They have to sit in the same classroom, listen to the same class and finish the same homework. As a result, for most students, no matter smart or not, those costs before college are quite similar.

The college entrance examination is an extremely important event for most students. Especially, when the college degree has become a necessityfor finding a proper job, failing to enter a college has even become a disaster and humiliation, both for the families and students. However, passing the exam isn't a big success. Due to the scarce and highly unequally distributed education resources, most students can't enter good colleges.

In most normal Chinese colleges, the courses are relatively simple and students don't have to study very hard to pass the exams. Essentially, almost all students that have entered college can graduate. As a result, GPA and college degrees can't tell much about the individuals' exact ability, only showing that the graduates have an ability in $[\underline{\theta}, \bar{\theta}]$.

In China, except a few prestigious universities such as Qinghua University and Beijing University, college degrees, not matter what that college is, are often just considered as a similar necessity for a proper job. Most firms don't care much about graduate applicants' education background unless they graduate from very good universities. So, we can just consider normal education in China as something like a uniform signal which involves similar costs for different individuals. To make that clear, let's look at Table 1.

Table 1. Some characteristics and results in Chinese education system

\begin{tabular}{|c|c|c|}
\hline Periods & Characteristics & Results \\
\hline $\begin{array}{l}\text { Before } \\
\text { college }\end{array}$ & $\begin{array}{c}\text { Standard training } \\
\text { Exam-oriented } \\
\text { Study under strict instruction } \\
\text { Absolute authority of schools and teachers } \\
\text { Little freedom for individuals }\end{array}$ & $\begin{array}{l}\text { Similar time (3 years in middle school and } 3 \text { years in } \\
\text { high school) } \\
\text { Similar effort (Preparing for the college entrance exam } \\
\text { under teachers' instruction) } \\
\text { Limited money cost }\end{array}$ \\
\hline In college & $\begin{array}{l}\text { Slack management } \\
\text { All students graduate }\end{array}$ & $\begin{array}{l}\text { Similar money cost (tuition fees and living costs) } \\
\text { Similar time cost ( } 4 \text { years) } \\
\text { A little effort (easy classes and exams) }\end{array}$ \\
\hline $\begin{array}{l}\text { College } \\
\text { diploma }\end{array}$ & Homogeneous diploma & $\begin{array}{l}\text { No selection } \\
\text { Inefficient signaling for individuals' ability }\end{array}$ \\
\hline
\end{tabular}

Based on that background knowledge, we can build a model that can reflect some basic facts in Chinese normal high education.

\section{Education choices}

We indicate with $\mathrm{E}=\{\mathrm{u}, \mathrm{g}\}$ the education choice undertaken in order to maximize their expected utility. Here $\mathrm{u}$ represents undergraduate and g represents graduate. The cost of acquiring undergraduate education is normalized to 0 . When students decide to invest in graduate education, they need to pay a cost, both in money and in time. We use $c$ to represent that cost. That cost $\mathrm{c}$ will be negatively related to individual ability $\theta$. Individual ability is determined at birth. For example, brilliant students need less time and money to get graduated. The cost of education $c(\theta, \mu)$ determines the share of graduates in the labor market. As Spence (1973) pointed out, as an efficient signaling tool, education cost should be negatively related to individual's ability. At least a part of education costs follows that rule, which I called variable education costs (VEC). However, there are also some costs of education that irrelevant to individual's ability. For simplicity, Here I refer it as constant education costs (CEC). Total education cost (TEC) should be a weighted average of both, just as shown in Equation (6)

$$
c(\theta)=(1-\mathrm{e}) \mu+\mathrm{e} \mu \frac{\theta^{\text {average }}}{\theta}
$$

$\mu$ here is the CEC. The VEC $=\mu \frac{\theta^{\text {average }}}{\theta}$ deserves more explanation. As I assumed earlier, the average ability is the critical point of whether higher education is socially profitable. Here I further assume average ability is the critical point of where the VEC is equal to CEC. In other words, only individual with higher than average ability can save their 
education costs through VEC, those individuals with inferior intelligence than average are discouraged from receiving higher education by a higher education cost in VEC. In this model, we use average ability as a very important standard. For an average ability individual, both kinds of education are at the same price $\mu$. I refer this price $\mu$ as "underlying education cost" (UEC) for CEC and VEC. As we want to compare the signaling efficiency, we need to control "underlying education cost" the same in CEC and VEC. In the following analysis, I don't change $\mu$ anymore, so we just need to consider the relationship between $\theta$ and c. We have

$$
e \in[0,1]
$$

Here $e$ is the weight of VEC in TEC. The higher e is, the more efficient signal education will be. The intuitive is that with higher e, the education cost for high ability individuals will be lower and the education cost for low ability ones will be higher. As a result, in general, the average ability level in graduates will rise and the average ability in undergraduates will fall. So, education level can be very powerful in distinguish between high ability and low ability.

However, this is not the case in China. In most less developed areas in China, students there don't enjoy the basic election mechanism, which means those more gifted students don't have the opportunity to show their talents and are treated as normal ones in the exam-oriented standard training system. Simultaneously, many less gifted students will be admitted into colleges and can easily graduate from those colleges, which will lower the generally ability level of graduates.

Obviously, the higher $\mu$ is, the higher $\operatorname{TEC}=c(\theta)$ will be, and the higher $\theta$ is (except the extreme case of e=0), the lower TEC will be.

Following the thought of Spence (2002), we start our analysis from the simplest case. In that case,

$$
c(\theta)=\mu
$$

So long as $w_{g}^{h}-\mu>w_{u}^{l}$, an individual will choose to get higher education. If

$$
\mu<\underline{\theta}-1
$$

In that extreme case, even individual with the lowest ability find it is profitable to acquire college degree. That means in a society, everyone can enjoy extremely cheap higher education. The productivity improvement for every individual is higher than his education cost. It is profitable both for the individual and for the whole society. In that situation, the signaling effect of education is not important. Consequently, asymmetry information lower signaling efficiency is not a problem at all.

But the reality is quite different from that low-education-cost utopian. Even in most developed countries, education is expensive both in time and money. Although some countries enjoy "free higher education", the economic burden is just transferred to tax-payers, not vanished. "Free higher education" also involves high cost in time and thus the opportunity cost of income. As a result, most people in the world have to consider very carefully about receiving higher education.

Here, we assume only for those individuals with higher than average ability, their productivity improvements due to higher education will be higher than the education cost. ${ }^{4}$ For those with lower ability than average, their productivity improvement can't compensate their education cost.

In an economy with perfect information, a worker's wage is always equal to his productivity, an individual will choose to receive higher education if

$$
\theta-\mu>1
$$

that is

$$
\mu<\theta-1
$$

In that case, a worker's education cost and benefit are equal to the whole society's cost and benefit. Individuals' profit maximization will automatically lead to social optimal outcome. Of course, we don't need signals under perfect information.

D. The minimum signaling efficiency case

However, if we walk out of the perfect information utopia and take the asymmetry information into consideration, there will be a pooling equilibrium. Individuals with different abilities are pooled together and get the same wage.

\footnotetext{
${ }^{4}$ That may not be the case in all countries. But theoretically, there should be a point, no matter it is below average ability or above average ability, determines whether an individual can get more productivity improvement than education costs.
} 
We assume after higher education marketization, high ability ones will choose to receive education first, and those with lower ability will follow if they find it is profitable. If the lowest ability in graduates is $\theta$, then the average productivity of graduates is $\frac{\theta+\bar{\theta}}{2}$, the average productivity improvement comparing to the undergraduates will be $\frac{\theta+\bar{\theta}}{2}-1$. In the critical ability point $\theta^{*}$, where individuals find it is indifferent whether receiving education or not, the wage improvement should equal the critical education cost:

$$
\frac{\theta^{*}+\bar{\theta}}{2}-1=c\left(\theta^{*}\right)
$$

To get all individuals receive higher education, we just need

$$
\mu \leq \theta^{\text {average }}-1=\frac{\theta+\bar{\theta}}{2}-1
$$

This may lead to inefficient outcome in society's point of view. To see how this inefficiency will lead to social welfare loss, we assume $\mu=\frac{\theta+\bar{\theta}}{2}-1-\sigma, \sigma \rightarrow 0^{+}$. That is, $\sigma$ is positive but is infinitely small. In that case, all individuals will get higher education. However, we can see $\frac{\theta+\bar{\theta}}{2}-\mu-1=\sigma \rightarrow 0^{+}$, the total surplus of education is nearly 0 . In this situation, education doesn't make any difference in total social welfare. And as we assume those surplus all goes to individual workers. This outcome also means that all individuals have almost the same net wage (wage net of education cost) and thus the same utility as when there is no higher education at all. If we consider the opportunity cost of investing in other more socially profitable activities, such higher education is a pure waste of social resources.

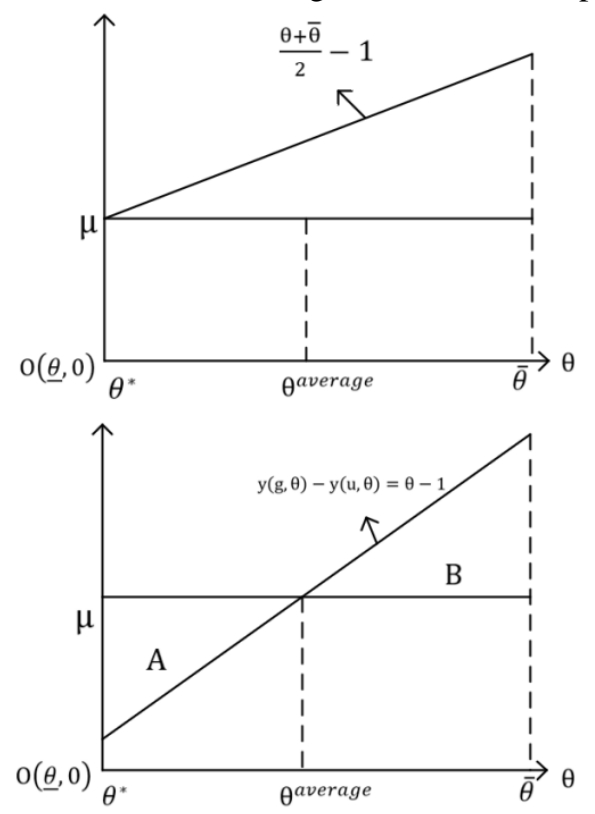

Figure 4. The minimum signaling efficiency

Source: Drawn by the author

We can see that very clearly in Figure 4. (To make things simple, we set $O(\underline{\theta}, 0)$ as the original point). Everyone choose to get higher education, which is a privately rational but socially inefficient situation. $\mathrm{S} \Delta \mathrm{A}$ represents social net loss due to overeducation of low ability individuals, whose productivity improvement is less than education $\operatorname{cost}^{5}$. $\mathrm{S} \Delta \mathrm{B}$

\footnotetext{
${ }^{5}$ In fact, the social net loss due to overeducation of low ability individuals should be $\int_{\underline{\theta}}^{\theta^{\text {average }}}[\mu-(\theta-1)] f(\theta) d \theta=\int_{\underline{\theta}}^{\theta^{\text {average }}}[\mu-(\theta-1)] \frac{1}{\bar{\theta}-\underline{\theta}} d \theta=\frac{1}{\bar{\theta}-\underline{-}} \int_{\underline{\theta}}^{\theta^{\text {average }}}[\mu-(\theta-1)] d \theta=\frac{1}{\bar{\theta}-\underline{\theta}} \mathrm{S} \Delta \mathrm{A}$
} 
represents social surplus due to education of high ability individuals, whose productivity improvement due to higher education is more than education cost. As the two right triangles have the same height and base, obviously $\mathrm{S} \triangle \mathrm{A}=$ $\mathrm{S} \Delta \mathrm{B}$. Total social surplus is 0 .

E. The maximum efficiency case

To improve total social welfare and make education profitable, we must select those with higher ability to receive higher education. With the premise of asymmetry information, the only way to do that is to improve the signaling efficiency of education. In the maximum efficiency, e=1,

$$
c(\theta)=\mu \frac{\theta^{\text {average }}}{\theta}
$$

In that case, an individual will choose to get higher education when

$$
\mathrm{w}(\theta, \mathrm{g})-\mu \frac{\theta^{\text {average }}}{\theta}>\mathrm{w}(\theta, \mathrm{u})
$$

And we know

$$
w(\theta, \mathrm{g})=\frac{\bar{\theta}+\theta^{*}}{2}, w(\theta, \mathrm{u})=1
$$

That means an individual will choose to get high education if

$$
\frac{\bar{\theta}+\theta^{*}}{2}-1>\mu \frac{\theta^{\text {average }}}{\theta}
$$

In the critical point $\theta^{*}$

$$
\frac{\bar{\theta}+\theta^{*}}{2}-1=\mu \frac{\theta^{\text {average }}}{\theta^{*}}
$$
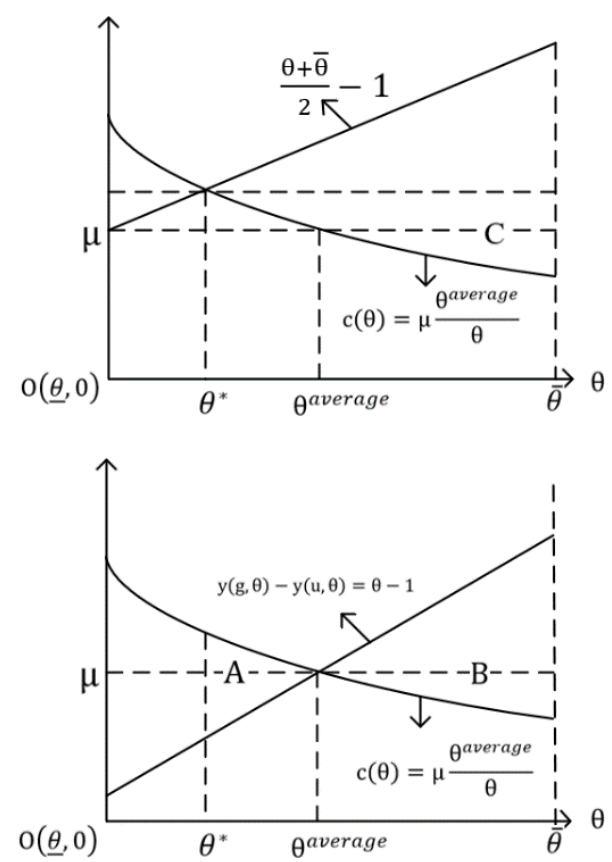

Figure 5. The maximum signaling efficiency

But we notice that $\frac{1}{\bar{\theta}-\underline{\theta}}$ is a constant. So, we can just consider $\frac{1}{\bar{\theta}-\underline{\theta}}$ as a measurement unit. In comparison, we don't need to involve that measurement unit. We can just compare the area directly. This simplification will apply to all the following analysis. 
Source: Drawn by the author

From Figure 5, we can find the social surplus and individual graduate wages increase dramatically. Intuitively, we can see the area A seems much smaller than B. To prove it seems a little complex. Luckily, we don't need to do that directly. We know from definition that A represents the social net loss due to overeducation of low ability individuals, and B represents social surplus due to education of high ability individuals. $\mathrm{C}$ represents the net gain of higher education for individuals, which have the same meaning as total surplus. So, we have $S_{B}-S_{A}=S_{C}$. So long as the wages for graduates are larger than their education cost, there will always be a positive social surplus, which is represented by $S_{C}$.

An interesting thing is that even in the maximum efficiency in our model, there are still some low ability individuals (not the lowest, of course) being over educated. For them, getting higher education is profitable because they are pooled with those higher ability ones and share their income. Those low ability individuals are free riders of higher education. They get more than their fair share income of the cost of high individuals' income. The only difference between an efficient signal and an inefficient signal is how serious that "Free Rider Problem" is.

If we want to know the exact amount of social surplus with maximum signaling efficiency, we just need to calculate $S_{C}$.

From $c(\theta)=\mu \frac{\theta^{\text {average }}}{\theta}$, we can get the inverse function

$$
\begin{array}{r}
\theta(\mathrm{c})=\mu \frac{\theta^{\text {average }}}{\mathrm{c}} \\
S_{C}=\int_{c(\bar{\theta})}^{c\left(\theta^{*}\right)}(\bar{\theta}-\theta(\mathrm{c})) d c
\end{array}
$$

If we have the exact number of parameters, we can get $S_{C}$ by equation (19) (20).

F. The middle cases

Now, let's move on to the cases that are not so extreme. What if e is something between 0 and 1 ? We can regard these situations as something between the minimum and maximum efficiency. As e is increasing, the situation will be more similar to the maximum efficiency.

$$
\begin{array}{r}
c(\theta)=(1-\mathrm{e}) \mu+\mathrm{e} \mu \frac{\theta^{\text {average }}}{\theta} \\
\text { VEC }=\mathrm{e} \mu \frac{\theta^{\text {average }}}{\theta}
\end{array}
$$

We can see that very clearly in Figure 6. To make it easy for analysis, we just draw a picture of VEC on the right to show the changes in e. As e decreases, the VEC picture is squashed flater and flater. The center of VEC picture, however, is fixed. It's place in the left picture is $\left(\theta^{\text {average }}, \mu\right)$, in the right picture is $\left(\theta^{\text {average }}, e \mu\right)$. We can find e just decides how much difference the signaling function can make in the higher education system. When $\mathrm{e}=0$, the VEC picture is squashed to a straight line, signaling function totally vanishes.

There are three situations with different e. When e is large, we can see the critical ability $\theta^{*}$ is close to $\theta^{\text {average }}$. That is, very few low ability individuals are overeducated, most people enjoy a productivity improvement higher than education cost. As a result, the social surplus of higher education, or $S_{C}$, is also very large. The graduates' wage is very high. 


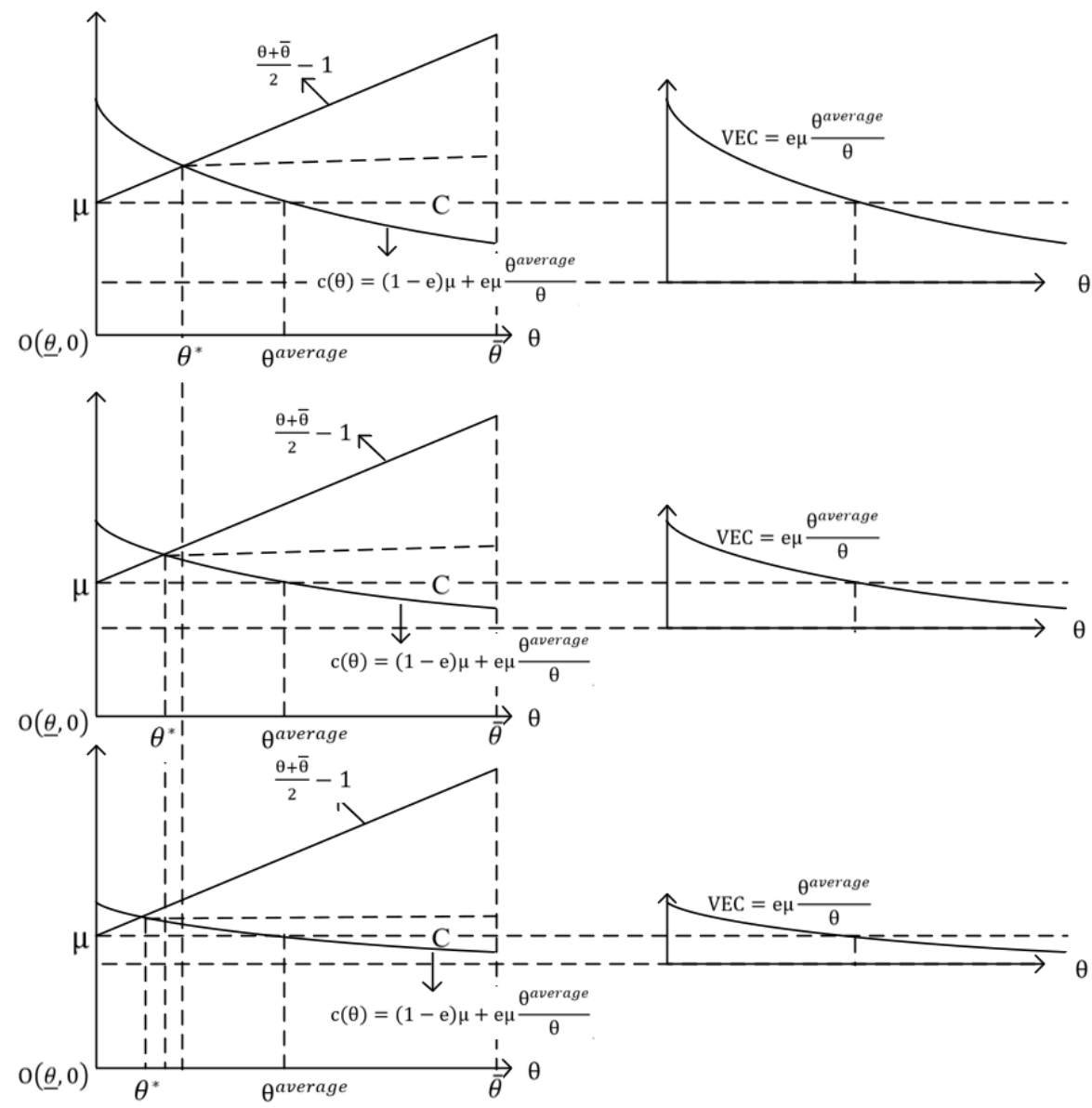

Figure 6. Comparison of different signaling efficiency

Source: Drawn by the author

However, as the signaling efficiency decreases, things begin to change. We can find the high education system become increasingly inefficient in selecting "proper guys". More and more low ability individuals enter the higher education system. For them, getting higher education is still a good thing, as the future income improvement of their own can cover their education cost. However, for the society, higher education becomes less and less efficient in improving workers' average productivity. As a result, the social surplus of higher education, or $S_{C}$, decreases dramatically, the graduates' wage also becomes very low, which is the case in China.

\section{The Model with Signaling Efficiency and Education Arms Race}

First, we take the 'hierarchy effect' into consideration. Education hierarchy is a pyramid where the higher stages are increasingly difficult to reach. In traditional Eastern Society, people value education not only because it can bring them economic benefits but also psychology reasons. Higher education is symbol of social status.

In many developed countries, overeducation is also a very big problem. Besides higher income, high education has different meanings, such as a symbol of social status (Veblen, 1899). People with higher education level usually despise those with lower education. People with lower education usually envy those with higher education. It is not just because of economic reasons, but also for honor and reputation. The roots are in Chinese culture. As we all know, China is an East Asia country with deep Confucian condition. Higher education usually provides individuals more respect from others. But in this comparison game, the sum is zero. Because when you are respected, someone else will be despised. Just as the Figure 7 shows.

In Figure 7, on the left, there are very few graduates, such as 0.25 proportion in the whole work force. Then the proportion of undergraduates is 0.75 . We assume the degree of respect $r$, is proportional to the proportion of people with lower education. That is $0.75 \mathrm{r}$. So, the total utility of graduates due to respect will be $0.75 \mathrm{r}^{*} 0.25$. For the same reason, the degree of despise is also proportional to the proportion of people with higher education. In this case, it is negative utility $-0.25 \mathrm{r}$. So, the total utility of undergraduates due to despise will be $-0.25 \mathrm{r}^{*} 0.75$. We can see $0.75 \mathrm{r} * 0.25-0.25 \mathrm{r} * 0.75=0$. It is a zero-sum game. 
If we increase the proportion of graduates to a number a $>0.25$, like on the right of Figure 1 , Then the total utility of graduates due to respect will be (1-a)ra. The total utility of undergraduates due to despise will be -ar(1-a). We can find $(1-a) r a-a r(1-a)=0$. No matter what a is, it is always a zero-sum game.

To make things easier to understand, just imagine higher education is something like an expensive car. If you have an expensive car, you can show it off to your neighbor. That will make you feel good if your neighbor only has an ordinary car. But in the same time, your neighbor will feel bad. In order to compete with you, he also buys a luxury car that he doesn't really need. In the end, no one will feel good from comparison. We can say this is a zero-sum game because the total utility from comparison is zero. But if we consider the wasted money, both of you are worse off. This is the same case in Chinese education market.

In 1979, China ended the Cultural Revolution and restored the college entrance examination. In the following several years, being admitted into a college is extremely difficult and college graduates are very few. This is like the left case in Figure 7. At that time, receiving higher education means not only a brilliant future, but also a great honor. Failures in the college entrance examination are very common and are not considered as a stigma. However, since the enrollment expansion in colleges and universities in 1998, being admitted into college (except those prestigious ones) became a common thing, or even a necessity for most students. Passing the college entrance examination is nothing, but failing to enter a college become a disaster and a big humiliation. This is like the right case in Figure 7.

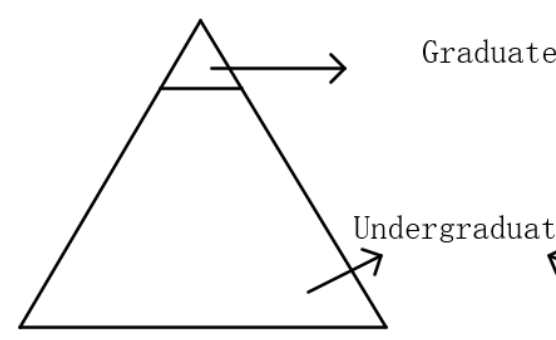

(1)

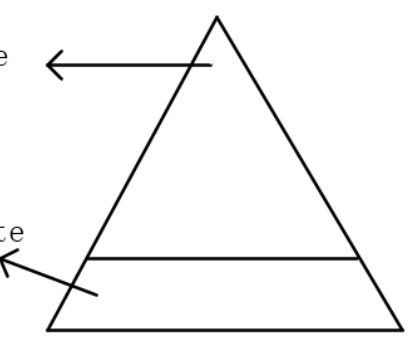

(2)

Figure 7. Two different education hierarchies

Source: Drawn by the author

$$
\begin{aligned}
& \mathrm{U}(\mathrm{E}, \theta)=\mathrm{w}(\mathrm{E}, \theta)+\mathrm{R}(\mathrm{E}) \\
& \mathrm{R}(\mathrm{E})=\left\{\begin{array}{r}
(1-a) r, \text { if graduated } \\
- \text { ar }, \text { if undergraduated }
\end{array}\right.
\end{aligned}
$$

If we add this hierarchy effect into our model, luckily, we don't need to make many changes. The reason is that the hierarchy effect is simpler than it seems. When an individual want to decide whether or not receiving higher education, he just needs to compare:

$$
\begin{array}{r}
\mathrm{U}(\mathrm{g}, \theta)-\mathrm{U}(\mathrm{u}, \theta)=\mathrm{w}(\mathrm{g}, \theta)+\mathrm{R}(\mathrm{g})-\mathrm{w}(\mathrm{u}, \theta)+\mathrm{R}(\mathrm{u}) \\
\mathrm{U}(\mathrm{g}, \theta)-\mathrm{U}(\mathrm{u}, \theta)=\mathrm{w}(\mathrm{g}, \theta)-\mathrm{w}(\mathrm{u}, \theta)+r
\end{array}
$$

So, when comparing graduate and undergraduate states, that vanity is just like a fixed number of education bonus. That makes out following analysis much simpler. So, we just need to draw a line $\frac{\theta+\bar{\theta}}{2}-1+r$ to represent the evergage utility improvement when $\theta$ is the critical point. When an individual find receiving higher education can give him high utility, he will choose to receive high education.

Let's look at Figure 8. We can find if we consider the education arms race, $\theta^{*}$ will move left. And with $c(\theta)$ and $\mathrm{y}(\mathrm{g}, \theta)-\mathrm{y}(\mathrm{u}, \theta)=\theta-1$ stay unchanged, this means the area A will become bigger. So, $S_{B}-S_{A}$ will become smaller, which means less social welfare surplus. 


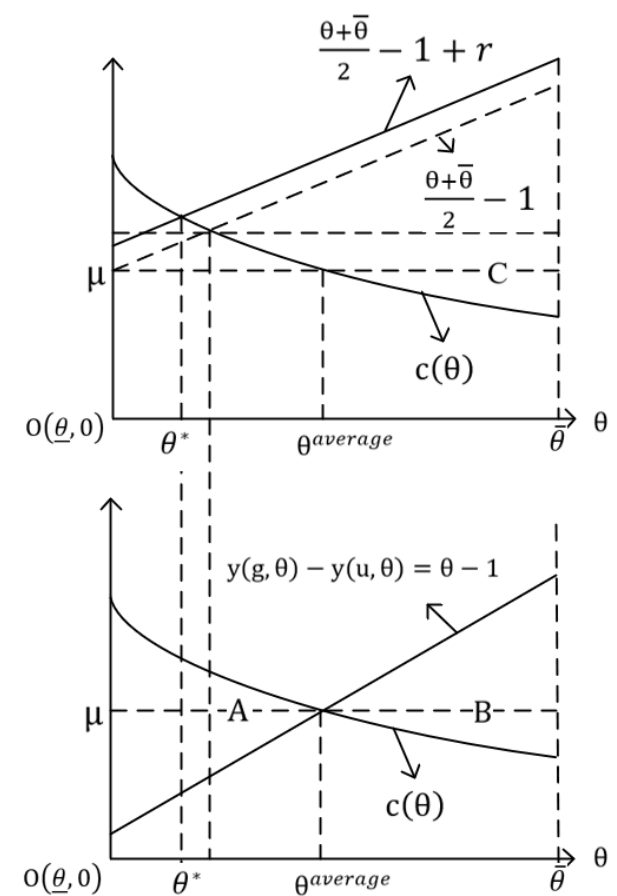

Figure 8. Education arms race and social welfare loss

Source: Drawn by the author

\section{Extensions}

\section{A. Signaling efficiency dilemma}

What is most interesting is that with a vanity for education, an efficient signaling education system may provide worse outcome than an inefficient one. We can call this "Signaling efficiency dilemma". Here we should look into "theory of the second best". In economics, the theory of the second best concerns the situation when one or more optimality conditions cannot be satisfied. If one optimality condition in an economic model cannot be satisfied, it is possible that the next-best solution involves changing other variables away from the values that would otherwise be optimal. In other words, if one distortion in the market cannot be removed, introducing another distortion may counteract the first, leading to a more efficient outcome.

To see that clearly, I draw another Figure. In Figure 9, area A and area B are the two areas inside the two real lines: $c(\theta)$ and $\mathrm{y}(\mathrm{g}, \theta)-\mathrm{y}(\mathrm{u}, \theta)=\theta-1$. Please compare the area A and B. You can find $S_{A}>S_{B}$. The reason is simple: The ability's effect in reducing education cost is marginal diminishing. The less brilliant guys cost more than those brilliant ones save. If we draw a dashed line tangent to the education cost line at $\left(\theta^{\text {average }}, \mu\right)$, that dashed line and $\mathrm{y}(\mathrm{g}, \theta)-$ $y(u, \theta)=\theta-1$ just formed two congruent triangles. Area A is bigger than those two congruent triangles and area B is smaller than those two congruent triangles. 

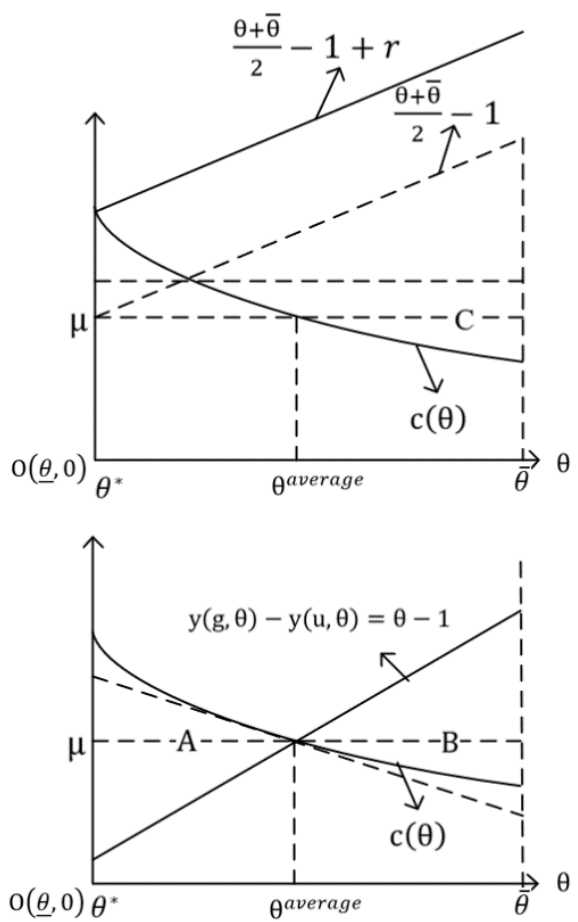

Figure 9. The signaling efficiency dilemma

Source: Drawn by the author

B. Diplomaism and money worship

We can call the incentive behind education arms race as "diplomaism", or "credentialism". But what is the reason behind diplomaism? Generally, there are two main reasons. One is that higher education level is a symbol of knowledge and intelligence, which is respectable. The other is that higher education level means higher income. So, the second reason means people like high education partly because they want to be considered richer than others.

To see that clearly, let's look at Figure 10. We can find that there is an intersection of diplomaism and money worship, which means people admire highle educated guys because their diploma can bring them higher income. If this intersection occupies bigger proportion of diplomaism, this means the society is more practical. If the diplomaism is included in money worship, that will be a good thing for social welfare, at least economically.

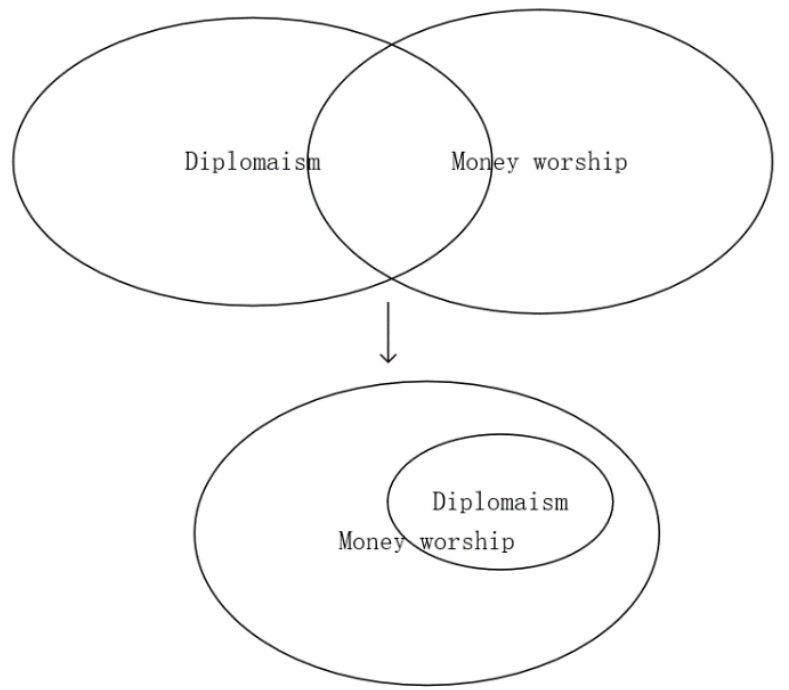

Figure 10. The intersection of diplomaism and money worship

To understand that, let's see Figure 11. If the diplomaism is just another kind of money worship, that means $r$ is totally determined by the net income improvement (net of education cost) due to high education, then we can create a function $\mathrm{m}(\theta)$, represent the money worship intensity if $\theta$ is the critical point (if $\theta=\theta^{*}$ ). The higher $\theta$ is, that higher average 
income for graduates will be. When $\theta^{*}=\underline{\theta}$, that is the minimum signaling efficiency and the wage improvement will be equal to the education cost. At that time, people will not envy college graduates because economically, high education means nothing. When $\theta^{*}=\bar{\theta}$, that means only the most gifted guys receive higher education and they are paid by their productivity, which is also the highest. In that situation, graduates receive maximum respect $r$ for their high income. If we assume the respect and income bonus are proportional, we have

$$
\mathrm{m}(\underline{\theta})=0, \mathrm{~m}(\bar{\theta})=\mathrm{r}, \mathrm{m}^{\prime}(\theta)>0, \mathrm{~m}^{\prime \prime}(\theta)=0
$$

That means if high education can't bring people net income improvement, people won't admire those with higher

education level. Then we draw a line $\frac{\theta+\bar{\theta}}{2}-1+m(\theta)$ We can find that will bring a much more efficient outcome than in Figure 8, much closer to the outcome without education arms race. So, in a society where people worship money, perhaps many such kind of distortions can be mitigated.

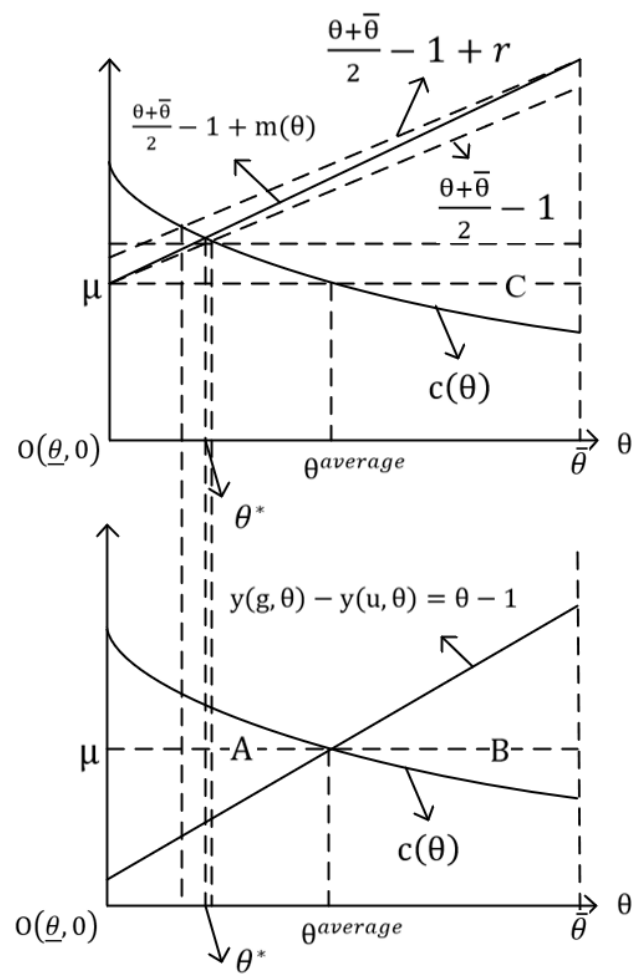

Figure 11. Diplomaism as a kind of money worship

C. Rent seeking for prestigious universities in college entrance exams ${ }^{6}$

As I have mentioned before, in normal universities, high individuals have difficulties in signaling their ability and have to receive average wage, which is unpleasant to them. In order to escape from this unfair egalitarian pooling, an individual who has ability close to $\bar{\theta}$ may want to study hard and get higher score in the college entrance exams. However, the quota of prestigious students is fixed by the government. As a result, fearing to lose their superior positions, those who have ability above $\bar{\theta}$ also have to work hard to avoid being surpassed by their counterparts with a little lower ability. As a result, huge amount of time and energy will be wasted on those "rent-seeking" activities.

To see that more clearly, let's look at Figure 12. Here we extend our model to include prestigious universities. ${ }^{7} \mathrm{We}$ assume the prestigious universities can increase individuals' productivity dramatically. What's more, those universities can provide proofs about individuals' exact ability. For example, top universities' scholarships and GPAs are very important in job hunting because most people think they are very persuasive. However, prestigious universities are very scarce in China and only the most brilliant ones have opportunities to enter them. The original necessary cost for

\footnotetext{
${ }^{6}$ To make it simpler, we don't consider the education arms race in the following analysis.

${ }^{7}$ Notice here we don't assume uniform distribution for ability above $\bar{\theta}$. So, we can't use areas to represent welfare directly. Luckily, we can still make some simple comparison.
} 
receiving such education may not be very large for high-ability individuals. But in the fierce competition of Chinese college entrance exams, one must score high enough to prove he does have high ability. Pursuing such unnecessarily high scores is essentially a kind of rent seeking activity because it consumes huge amount of time, money and energy but doesn' univerisities t provide any value for the society. In the end, those super-high-ability individuals do have what they want, but at a super-high price.

That rent-seeking problem can be very serious when the signaling efficiency of normal colleges is very low. The reason is simple: those with relatively high ability (but still below $\bar{\theta}$ ) will not to be pooled with those low ability ones and receive average wage. The only way to escape that fate is to study harder in the college entrance exams and score higher. However, the quota of prestigious universities is fixed. Those with super-high ability won't give up their position in prestigious universities. So, they also study harder and score even higher. That process will continue until in the end, the rent-seeking cost is so high that prestigious universities are not attractive to those with ability below $\bar{\theta}$.

To see that clearly, let's look at Figure 12. We assume prestigious universities' graduates will be paid according to their real productivity, which is $y^{p}(\theta)$, the necessary cost for receiving prestigious university education is $c^{p n}(\theta)$. Obviously, in the critical point $\bar{\theta}$,

$$
y^{p}(\bar{\theta})-1-c^{p n}(\bar{\theta})>\frac{\theta^{*}+\bar{\theta}}{2}-1-c(\bar{\theta})
$$

So, there is a "rent" in prestigious universities. Students with ability a little lower than $\bar{\theta}$ will want to get into prestigious universities. At the same time, the most brilliant ones will want to guard their privileges. The result is that the scores (which involves much time, money and energy) for prestigious universities in the college entrance exam rises to a degree where an individual with ability $\bar{\theta}$ is indifferent in whether go to prestigious universities or not. If we use ${ }_{c^{p r}}(\theta)$ to represent that rent-seeking cost, mathematically, we have

$$
y^{p}(\bar{\theta})-1-\left[c^{p n}(\bar{\theta})+c^{p r}(\theta)\right]=\frac{\theta^{*}+\bar{\theta}}{2}-1-c(\bar{\theta})
$$

If the signaling efficiency is very low. That is, if $\theta^{*}$ is very small, $\frac{\theta^{*}+\bar{\theta}}{2}-1-c(\bar{\theta})$ can be very close to 0 . In that case, not only normal colleges graduates find high education meaningless in economy, even those prestigious universities graduates have to work so hard that their net gain in prestigious universities drop dramatically. For those with ability a little higher than $\bar{\theta}$, their wage improvement and productivity improvement will almost equal to their education cost. Obviously, those rent-seeking activities in order to get unnecessarily high scores is a pure waste of resources, especially economically. In China, the over-competition for prestigious universities entrance is also an increasingly serious problem. Here we find the inefficient signaling of normal colleges is one important reason.

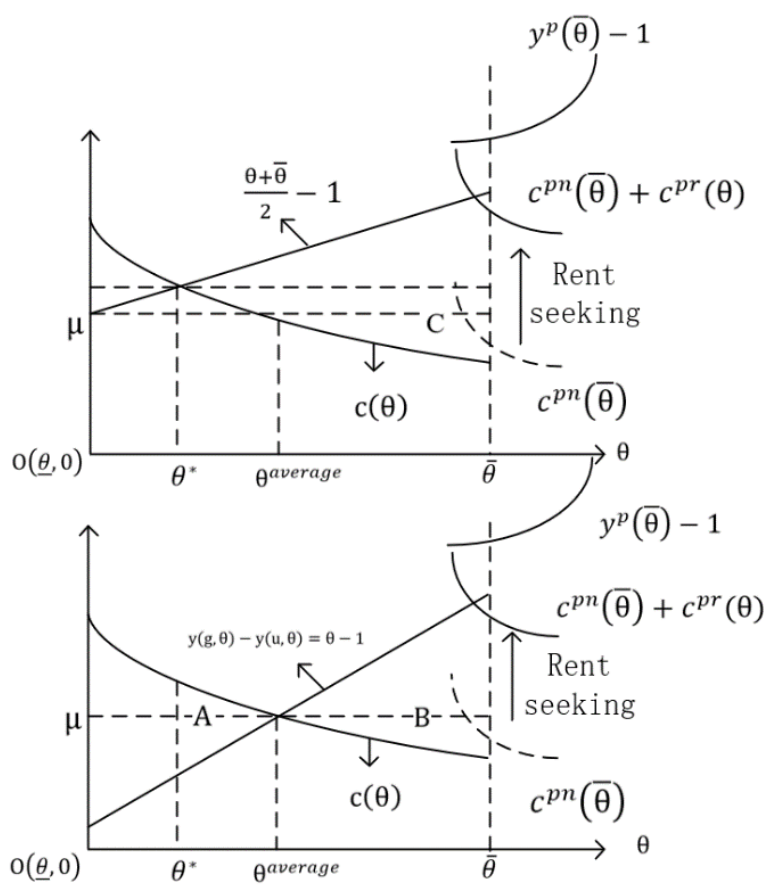

Figure 12. Rent-seeking for prestigious universities 


\section{Conclusions}

Through our analysis, we get some interesting conclusions.

First, because of the poor signaling efficiency, Chinese high education system includes too many low-ability individuals and lowers the average productivity of graduates. This result in total welfare loss of the whole society and lower wages for graduates.

Second, the education arms race, which is a zero-sum game itself, exacerbate the inefficient signaling problem and lowers the average productivity of graduates even further. Of course, this means more social welfare loss and even lower wage for graduates. Sometimes their wage is so low that the wage improvement due to high education can't even cover their education costs.

Third, even with the maximum efficiency system, if the education arms race is fierce enough, this may also result in low average productivity and wages of graduates. Sometimes this situation may be even worse than in the inefficient signaling system. The reason why it could be even worse is the diminishing return of the ability.

Fourth, in a society where people admire those with high degrees simply for the income improvement rather than pure vanity, the inefficient signaling and welfare loss problems will be less serious.

Finally, the inefficient pooling of normal high education will give those with higher ability (though not high enough to get into prestigious universities) an incentive to escape from this pool and go to prestigious universities. In order to guard their positions, those with higher abilities will work even hard to get unnecessarily high scores in college entrance exams, which is a kind of rent-seeking activity. It is a pure waste of social resources.

\section{Acknowledgements}

The author would like to thank two anonymous referees for their valuable comments and suggestions.

\section{References}

Arrow, K. J. (1973).Higher education as a Filter. Journal of Public Economy, July 1973, 2(3), 193-216. https://doi.org/10.1016/0047-2727(73)90013-3

Fitzsimons, P. (2015). Human capital theory and education. Encyclopedia of educational philosophy and theory. Springer Singapore, 1-4.

Kirkpatrick, R., \& Yuebing, Z. (2011). The negative influences of exam-oriented education on Chinese high school students: Backwash from classroom to child. Language testing in Asia, 1(3), 36. https://doi.org/10.1186/2229-0443-1-3-36

Ma, Yuchao, Donald, L., McCabe, \& Ruizhi, L. (2013). Students' Academic cheating in Chinese universities: prevalence, influencing factors, and proposed action. Journal of Academic ethics, 11(3), 169-184. https://doi.org/10.1007/s 10805-013-9186-7

Ordine, P., \& Rose, G. (2017). Too Many Graduates? A matching Theory of Educational Mismatch. Journal of Human Capital, 423-446. https://doi.org/10.1086/694455

Spence, M. A. (1899). Signaling in Retrospect and Informational Structure of Markets. A.E.R. 92, 434-459.

Spence, M. A. (1973). Job Market Signaling. Q.J.E, 87, 335-374. https://doi.org/10.2307/1882010

Veblen, T B. (1899). The Theory of the Leisure Class. Macmillan.

\section{Copyrights}

Copyright for this article is retained by the author(s), with first publication rights granted to the journal.

This is an open-access article distributed under the terms and conditions of the Creative Commons Attribution license which permits unrestricted use, distribution, and reproduction in any medium, provided the original work is properly cited. 